\title{
Letter to the editor regarding "A prospective double-blind randomized trial on ultrasound-guided versus blind intra-articular corticosteroid injections for primary frozen shoulder"
}

\author{
Zeng Zeng ${ }^{1} \cdot$ Cong-Xian Chen $^{1}$ (D)
}

Received: 10 August 2021 / Accepted: 11 August 2021 / Published online: 26 August 2021

(c) Springer Science+Business Media, LLC, part of Springer Nature 2021

\section{To the Editor,}

We read with great interest the article of Cho et al. [1] titled " A prospective double-blind randomized trial on ultrasoundguided versus blind intra-articular corticosteroid injections for primary frozen shoulder" in a recent issue of the journal. I have some queries on the article.

In the CONSORT guideline flow diagram part, Cho had 4 and 6 patients lost to follow-up in ultrasound group and blind group separately [1]. However, in results part, the author wrote there were no significant differences in the mean VAS, ASES, SSVs, and passive ROMs between the success $(n=77)$ and the failure groups $(n=13)$ at 3,6 , and 12 weeks after injection. Why the lost to follow-up patients (4 patients in ultrasound group and 6 in blind group) were counted in the follow-up patients? This is an obvious error.

Second query is, in the results part, the proportion of left-sided involvement was higher in the US group compared with blinded group $(p=0.003)$. Recent study shows with increasing daily activity by the dominant hand, this will lead to a slower rate of recovery on dominant hand [2]. So we wonder whether dominant/non-dominant hand will cause different prognosis or not.

Last, this study was double-blind randomized trial. That means both the operator and patients should keep unaware of which group will be allocated [3]. However, in methods part, intra-articular corticosteroid injections for US group and blinded group, all these procedures were performed by a single specialist (DHK) with 15 years of experience in the field. Obviously, the operator in this study knew which group the patient will be divided into by ultrasound or not. This is a clear violation of the random double-blind principle.

Yours Sincerely.

\section{Declarations}

Conflict of interest The author declares no conflict of interest.

Ethical approval This article does not contain any studies with animals performed by any of the authors.

\section{References}

1. Cho $\mathrm{CH}$, Min BW, Bae KC, Lee KJ, Kim DH. A prospective double-blind randomized trial on ultrasound-guided versus blind intra-articular corticosteroid injections for primary frozen shoulder. Bone Joint J. 2021;103-B(2):353-9.

2. Tang QY, Lai WH, Tay SC. The effect of hand dominance on patient-reported outcomes of carpal tunnel release in patients with bilateral carpal tunnel syndrome. J Hand Surg (Asian-Pacific Vol). 2017;22(3):303-8.

3. Lang TA, Stroup DF. Who knew? The misleading specificity of "double-blind" and what to do about it. Trials. 2020;21(1):697.

Publisher's Note Springer Nature remains neutral with regard to jurisdictional claims in published maps and institutional affiliations.
Cong-Xian Chen

kema320@qq.com

1 Department of Ultrasound, Zhejiang Provincial People's

Hospital, Hangzhou, Zhejiang, China 